\title{
Valsartan ameliorates podocyte loss in diabetic mice through the Notch pathway
}

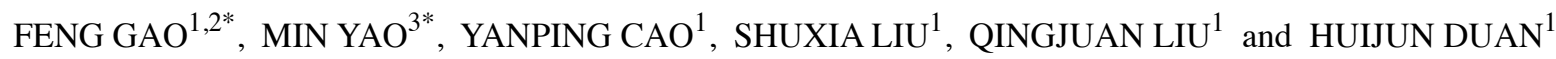 \\ ${ }^{1}$ Department of Pathology, Hebei Medical University, Shijiazhuang, Hebei 050017; \\ ${ }^{2}$ Department of Pathology, The Third Hospital of Hebei Medical University, Shijiazhuang, Hebei 050051; \\ ${ }^{3}$ Department of Biochemistry, Hebei Medical University, Shijiazhuang, Hebei 050017, P.R. China
}

Received April 13, 2015; Accepted March 1, 2016

DOI: $10.3892 /$ ijmm.2016.2525

\begin{abstract}
The Notch pathway is known to be linked to diabetic nephropathy (DN); however, its underlying mechanism was poorly understood. In the present study, we examined the effect of Valsartan, an angiotensin II type 1 receptor antagonist, on the Notch pathway and podocyte loss in DN. Diabetes was induced in mice by an intraperitoneal injection of streptozotocin and and this was followed by treatment with Valsartan. Levels of blood glucose, kidney weight and body weight, as well as proteinuria were measured. Samples of the kidneys were also histologically examined. The relative levels of Jagged1, Notch1, Notch intracellular domain 1 (NICD1), Hes family BHLH transcription factor 1 (Hes1) and Hes-related family BHLH transcription factor with YRPW motif 1 expression (Hey1) in the glomeruli were determined by immunohistochemical analysis, western blot analysis and RT-qPCR. The B-Cell CLL/Lymphoma 2 (Bcl-2) and p53 pathways were examined by western blot analysis. Apoptosis and detachment of podocytes from the glomerular basement membrane were examined using a TUNEL assay, flow cytometric analysis and ELISA. The number of podocytes was quantified by measuring Wilms tumor-1 (WT-1) staining. We noted that the expression of Jagged1, Notch1, NICD1, Hes1 and Hey1 was increased in a time-dependent manner in the glomeruli of mice with streptozotocin (STZ)-induced diabetes. Moreover, in diabetic mice, Valsartan significantly reduced kidney weight and proteinuria, and mitigated the pathogenic processes in the kidneys. Valsartan also inhibited the activation of Notch, Bcl-2 and p53 pathways and ameliorated podocyte loss in the glomeruli of mice with STZ-induced diabetes. Taken together, these findings indicated that Valsartan exerted a beneficial
\end{abstract}

Correspondence to: Dr Huijun Duan, Department of Pathology, Hebei Medical University, 361 Zhongshan East Road, Shijiazhuang, Hebei 050017, P.R. China

E-mailduanhj999@163.com

*Contributed equally

Key words: diabetic nephropathy, Valsartan, Notch pathway, podocyte loss effect on reducing podocyte loss, which is associated with inhibition of Notch pathway activation in the glomeruli of diabetic mice.

\section{Introduction}

Diabetic nephropathy (DN) is one of the most common complications of diabetes and has become the most frequent cause of end-stage renal disease. Pathologically, DN is characterized by glomerular hypertrophy, excessive accumulation of the extracellular matrix (ECM), sclerosis and end-stage interstitial fibrosis (1). Podocytes, which are terminally differentiated epithelial cells, are one of the major cell types in the glomerulus, and they form a critical component of the glomerular filtration barrier. Podocyte loss results in proteinuria, an accumulation of ECM components and glomerulosclerosis, which is considered to be a potential, early pathological marker for DN (2-5). Podocyte apoptosis and detachment from the glomerular basement membrane are two main factors involved in the process of podocyte loss $(6,7)$.

Previous studies have demonstrated that the Notch pathway, which is involved in the regulation of cell differentiation, proliferation and apoptosis (8-10), plays an important role in the pathogenesis of DN $(11,12)$. In mammals, there are four Notch receptors (Notch1-Notch4) and five ligands, Jagged1, Jagged2, Delta-like (D11)1, D113 and D114] (13). Binding of the ligand and receptor induces a conformational change of the Notch receptor, resulting in an extracellular metalloprotease-mediated cleavage of the receptor, which enables $\gamma$-secretase-mediated protease cleavage and subsequent release of the Notch intracellular domain (NICD). It has been shown that the NICD is translocated into the nucleus where it activates the transcription of downstream genes, including Hes and Hey genes (14). Previous research has demonstrated that activation of the Notch pathway is related to podocyte apoptosis in diabetic patients and animals (15). Podocyte detachment from the glomerular basement membrane has been demonstrated in previous studies of type 1 and type 2 diabetes mellitus (DM), and quantitative histological support for a potential mechanism of functional impairment and potential sclerosis of glomeruli in diabetic glomerular injury has been provided (16). However, it was still unclear whether there was an association between podocyte detachment and activation of the Notch pathway in DN. 
Activation of the renin-angiotensin system (RAS) plays a critical role in the pathogenesis of DN. Angiotensin II (Ang II), is the main effector of and promotes glomerular injury in DN (17). Thus, inhibiting the production of Ang II and disrupting its function is key for the treatment of DN. Ang II mainly acts by binding to two specific receptors, angiotensin type 1 receptor (AT1R) and angiotensin type 2 receptor (AT2R). AT1R is responsible for the majority of the pathophysiological effects of Ang II in renal disease (18). Valsartan, an AT1R antagonist (AT1Ra), has been shown to exhibit a protective effect on renal function, which is independent of its effect on lowering blood pressure. Ang II promotes the proliferation and migration of vascular smooth muscle cells via the Notch pathway (19). However, the effect of Ang II on the Notch pathway in relation to podocyte loss in cases of DN was not fully understood. In the present study, we hypothesized that Ang II mediates podocyte loss by activating the Notch pathway in a mouse model of streptozotocin (STZ)-induced diabetes. To test this hypothesis, mice with STZ-induced diabetes, which had been treated with Valsartan, were examined for changes in the Notch pathway, the B-Cell CLL/Lymphoma 2 (Bcl-2) and p53 pathway, cell apoptosis and podocyte detachment. We investigated the effect of Valsartan on the Notch pathway and podocyte loss, and further explored the underlying mechanism of glomerular injury in DN.

\section{Materials and methods}

Experimental animals. Male CD-1 mice, 5 weeks of age weighing 20-25 g, were purchased from Vital River Laboratory Animal Technology Co., Ltd., (Beijing, China) and housed in a pathogen-free animal facility with free access to food and water. The experimental protocols were approved by the Institutional Animal Care and Use Committee of Hebei Medical University (Shijiazhuang, China). The mice were injected intraperitoneally (i.p.) with STZ $(150 \mathrm{mg} / \mathrm{kg}$; Sigma Chemical Co., St. Louis, MO, USA) dissolved in $0.1 \mathrm{M}$ citrate buffer ( $\mathrm{pH} 4.5$ ) to induce DM. The mice in the control group were injected with an equivalent volume of saline $(150 \mathrm{mg} / \mathrm{kg})$. Three days after injection, diabetes mellitus (DM) was confirmed by a blood glucose (BG) concentration higher than $16.7 \mathrm{mmol} / \mathrm{l}$, which was determined using a glucometer (Johnson \& Johnson, New Brunswick, NJ, USA). Valsartan $(40 \mathrm{mg} / \mathrm{kg}$; Beijing Novartis Pharma Ltd., Beijing, China) was administered daily by gavage to the mice in the DM + Valsartan group. Mice in the control and DM groups received the same volume of distilled water daily by gavage. At 1, 2, 4 and 8 weeks after treatment, mice ( $\mathrm{n}=6 /$ group) were housed individually for $24 \mathrm{~h}$ in metabolic cages in order to collect mouse urine. The urine was used to measure urinary albumin over $24 \mathrm{~h}$ using an Immulite 1000 chemistry analyzer (Siemens AG, Munich, Germany), and the concentration of podocalyxin (PCX) was quantified using the competitive sandwich enzyme-linked immunosorbent assay (ELISA) kit according to the manufacturer's instructions (R\&D Systems, Inc., Minneapolis, MN, USA). Mice were deeply anesthetized using chloral hydrate, and blood samples of mice were obtained through the abdominal aorta and prepared to measure serum BG levels. Both kidneys were removed from the abdominal cavity of the mice: we isolated kidney tissue from adipose tissue, cut renal vasculature with scissors to obtain kidney tissue, and then kidneys were weighed. The sera were prepared to measure serum BG levels. Both kidneys were dissected and weighed. The left kidney was fixed in $4 \%$ paraformaldehyde in $0.01 \mathrm{~mol} / \mathrm{l}$ phosphate-buffered saline (PBS), and embedded in paraffin for tissue processing, histological examination and immunohistochemical staining. Part of the right kidney was minced with a razor blade, and glomeruli were isolated by filtration through nylon mesh using ice-cold $0.9 \%$ $\mathrm{NaCl}$ solution, as previously described (20). Remaining renal tissues were fixed in $70 \%$ alcohol for flow cytometric analysis.

Histological analysis. Paraffin-embedded renal tissue sections $(4 \mu \mathrm{m})$ were prepared and stained with hematoxylin and eosin (H\&E) and periodic acid-Schiff (PAS). Renal cortical sections were observed using light microscopy (BX50; Olympus, Tokyo, Japan), and glomerulardiameter was measured using TD2000 image analysis software (Tiandibainian, Beijing, China). At least 30 glomeruli/animal were examined. Glomerular diameter was measured using TD2000 image analysis software (Tiandibainian, Beijing, China).

Immunohistochemical analysis. Paraffin-embedded renal tissue sections $(4 \mu \mathrm{m})$ were deparaffinized with xylene and rehydrated in graded ethanol solution. Endogenous horseradish peroxidase (HRP) activity was blocked by pre-treatment with $3 \% \mathrm{H}_{2} \mathrm{O}_{2}$ for $10 \mathrm{~min}$ at room temperature. Antigen recovery was performed using a microwave. To block non-specific binding, the sections were incubated at $37^{\circ} \mathrm{C}$ for $30 \mathrm{~min}$ in PBS containing $10 \%$ goat serum. Finally, the sections were incubated with rabbit polyclonal antibodies against Notch1 (1:50 dilution; ab52301), NICD1 (1:50 dilution; ab8925) and Wilms tumor-1 (WT-1) (1:200 dilution; ab180840) (all from Abcam, Cambridge, UK), overnight at $4{ }^{\circ} \mathrm{C}$. On the following day, after incubation with the PV-9000 Polymer detection system (Zhongshan Golden Bridge Biotechnology Co., Ltd., Beijing, China), the sections were stained with 3,3-diaminobenzidine (DAB) and counterstained with hematoxylin. For negative controls the primary antibody was replaced with PBS. The expression of Notch1 in glomeruli was analyzed quantitatively by performing digital image analysis with Image Pro-Plus 5.0 image analysis software (Media Cybernetics, Silver Spring, MD, USA). The number of NICD1and WT-1-positive cells in the nucleus was counted in each glomerulus of the kidney sections ( $\mathrm{n}=6$ mice/group, mean $=25$ glomeruli/mouse) using light microscopy (BX50, Olympus). Positive cells in the glomeruli represented their expression in each group.

Western blot analysis. The glomeruli isolated from individual mice were homogenized and centrifuged at $435 \mathrm{x}$ g for $10 \mathrm{~min}$, and then treated for $60 \mathrm{~min}$ with ice-cold lysis buffer $(20 \mathrm{mmol} / \mathrm{l}$ Tris-HCl, pH 7.4, $2.5 \mathrm{mmol} / \mathrm{l}$ EDTA, $1 \%$ Triton $\mathrm{X}-100,10 \%$ glycerol, $1 \%$ deoxycholate, $0.1 \%$ SDS, $10 \mathrm{mmol} / 1$ $\mathrm{Na}_{4} \mathrm{P}_{2} \mathrm{O}_{7}, 50 \mathrm{mmol} / \mathrm{l} \mathrm{NaF}, 1 \mathrm{mmol} / 1 \mathrm{Na}_{3} \mathrm{VO}_{4}$ and $1 \mathrm{mmol} / 1$ PMSF). The protein concentration was measured using Bradford assay. After measuring protein concentration, the glomerular protein extracts were separated using SDS-PAGE and then transferred onto polyvinylidene membranes. The membranes were blocked with 5\% dried milk and incubated overnight at $4{ }^{\circ} \mathrm{C}$ with rabbit anti-Jagged1 (1:200 dilution; Santa Cruz Biotechnology, Inc., Santa Cruz, CA, USA); Notch1 
Table I. Changes in basic parameters in the control, DM and DM + Valsartan groups at 4 weeks.

\begin{tabular}{lccccc}
\hline Group & BG $(\mathrm{mmol} / \mathrm{l})$ & $\mathrm{UAE}(\mathrm{mg} / 24 \mathrm{~h})$ & $\mathrm{KW} / \mathrm{BW}(\mathrm{mg} / \mathrm{g})$ & MGD $(\mu \mathrm{m})$ & PCX $(\mathrm{ng} / \mathrm{ml})$ \\
\hline Control & $7.56 \pm 1.24$ & $0.32 \pm 0.06$ & $10.39 \pm 1.51$ & $54.83 \pm 5.21$ & $6.42 \pm 1.23$ \\
DM & $26.59 \pm 8.34^{\mathrm{a}}$ & $3.46 \pm 0.83^{\mathrm{a}}$ & $17.34 \pm 2.49^{\mathrm{a}}$ & $68.93 \pm 4.81^{\mathrm{a}}$ & $12.47 \pm 3.17^{\mathrm{a}}$ \\
DM + Valsartan & $27.39 \pm 8.68$ & $3.01 \pm 0.62^{\mathrm{b}}$ & $15.05 \pm 2.02^{\mathrm{b}}$ & $59.58 \pm 4.13^{\mathrm{c}}$ & $8.49 \pm 1.26^{\mathrm{c}}$ \\
\hline
\end{tabular}

${ }^{\mathrm{a}} \mathrm{P}<0.01$ vs. the control group; ${ }^{\mathrm{b}} \mathrm{P}<0.05$ and ${ }^{\mathrm{C}} \mathrm{P}<0.01 \mathrm{vs}$. the diabetes mellitus (DM) group. $\mathrm{BG}$, blood glucose; UAE, urinary albumin excretion; $\mathrm{KW}$, kidney weight; BW, body weight; MGD, mean glomerular diameter; PCX, podocalyxin.

(1:200 dilution), NICD1 (1:200 dilution), Hes family BHLH transcription factor 1 (Hes1) (1:2,000 dilution), and Hes-related family BHLH transcription factor with YRPW motif 1 expression (Heyl) (1:2,000 dilution) (all from Abcam); Bax (1:3,000 dilution), Bcl-2 (1:200 dilution) (both from ProteinTech Group, Inc., Chicago, IL, USA); cleaved caspase-3 (1:1,000 dilution; Cell Signaling Technology, Inc., Danvers, MA, USA); p-p53 (Ser37) (1:500 dilution), p53 (1:1,500 dilution) (both from Proteintech Group, Inc.); and $\beta$-actin (1:1,000 dilution; Santa Cruz Biotechnology, Inc.) polyclonal antibodies. After several washes, the membranes were incubated with goat anti-rabbit IgG HRP-conjugate (1:10,000 dilution; Proteintech) for $2 \mathrm{~h}$ at room temperature. Western blot protein bands were quantified following acquisition, and analysis of the image was subsequently performed using Image Station LabWorks 4.5 software (UVP, Inc., Upland, CA, USA). Finally, protein expression was quantified by comparison with the internal control $\beta$-actin.

Reverse transcription-quantitative polymerase chain reaction (RT-qPCR). Total RNA was extracted from the glomerular homogenate of individual mice using the SV Total RNA Isolation system according to the manufacturer's instructions (Promega Corp., Madison, WI, USA) and complementary DNA (cDNA) was synthesized via reverse transcription reaction. RT-qPCR amplification (Promega Corp.) was performed on an ABI 7500 Real-Time PCR system under the following conditions: $95^{\circ} \mathrm{C}$ for $30 \mathrm{sec}$ and 40 cycles of amplification $\left(95^{\circ} \mathrm{C}\right.$ for $5 \mathrm{sec}, 60^{\circ} \mathrm{C}$ for $30 \mathrm{sec}$ ). The following primer nucleotide sequences were used: Jagged1 forward, 5'-AGA AGT CAG AGT TCA GAG GCG TCC-3' and reverse, 5'-AGT AGA AGG CTG TCA CCA AGC CAA C-3'; Notch1 forward, 5'-GTG GAT GAC CTA GGC AAG TCG-3' and reverse, 5'-GTC TCC TCC TTG TTG TTC TGC A-3'; Hes1 forward, 5'-CAC GAC ACC GGA CAA ACC A-3' and reverse, 5'-GCC GGG AGC TAT CTT TCT TAA GTG-3'; Heyl forward, 5'-AAG ACG GAG AGG CAT CAT CGA G-3' and reverse, 5'-CAG ATC CCT GCT TCT CAA AGG CAC-3'; and 18S forward , 5'-CGC CGC TAG AGG TGA AAT TC-3' and reverse, 5'-CCA GTC GGC ATC GTT TAT GG-3'. All PCR primers were synthesized by Aoke Biotech (Beijing, China). The results were analyzed using the relative standard curve method of analysis $/ \Delta \mathrm{C}_{\mathrm{t}}$ method of analysis and 18S rRNA was used as the internal control.

Terminal deoxynucleotidyl transferase (TdT)-mediated dUTP nick-end labeling (TUNEL) assay. A fluorometric TUNEL system was obtained from Promega Corp. Renal tissue sections were deparaffinized with xylene and rehydrated in a graded ethanol series. Subsequently, $100 \mu \mathrm{l}$ of $20 \mu \mathrm{g} / \mathrm{ml}$ Proteinase K solution was added for $10 \mathrm{~min}$ at room temperature. Subsequently, we added $100 \mu 1$ of equilibration buffer at room temperature for $10 \mathrm{~min}$, and $50 \mu \mathrm{ldT}$ reaction mix was added to the cells for $60 \mathrm{~min}$ at $37^{\circ} \mathrm{C}$. The slides were immersed in $2 \mathrm{X}$ saline sodium citrate (SSC) for $15 \mathrm{~min}$. Propidium iodide (PI) was added to stain all cells. Localized green fluorescence of apoptotic cells was detected against a red background using fluorescence microscopy.

Flow cytometric analysis. Single cell suspension was obtained from the glomeruli (through a $400-\mu \mathrm{m}$ nylon filter) and resuspended in PBS containing $25 \mu \mathrm{g} / \mathrm{ml}$ RNase and $0.5 \%$ Triton $\mathrm{X}-100$. The samples were then incubated with $50 \mu \mathrm{g} / \mathrm{ml}$ PI at $4^{\circ} \mathrm{C}$ for 30 min and analyzed using an Epics-XLII flow cytometer (Beckman Coulter, Miami, FL, USA).

Statistical Analysis. Each experiment was repeated at least three times. Data are expressed as the means \pm standard deviation (SD) and were analyzed using one-way analysis of variance (ANOVA). A P-value $<0.05$ was considered to indicate a statistically significant difference.

\section{Results}

Activation of the Notch pathway in the glomeruli of diabetic mice. We noted that, compared with the control group, western blot analysis indicated that the protein expression of Jagged1, NICD1, Hes1 and Heyl began to increase at week 1, peaked at week 4 and decreased at week 8 in the glomeruli of diabetic mice $(\mathrm{P}<0.01)$ (Fig. 1A and B). Notch1 protein expression in the glomeruli of diabetic mice was increased compared with the control mice $(4.5$-fold, $\mathrm{P}<0.01)$. However, no significant difference in Notch1 expression were observed at different time points in the DM group $(\mathrm{P}>0.05)$. The mRNA levels of Jagged1, Notch1, Hes1 and Heyl began to increase at week 1, peaked at week 2 and slightly decreased in the glomeruli of the diabetic group, compared to the control group $(\mathrm{P}<0.05$ or $\mathrm{P}<0.01)$ (Fig. 1C).

Changes in basic parameters. As shown in Table I, the BG and urinary albumin excretion (UAE) levels were significantly higher in the DM group at 4 weeks compared to the control group $(\mathrm{P}<0.01)$. Treatment with Valsartan did not modulate hyperglycemia: BG concentrations were similar in both DM groups $(P>0.05)$. However, the amount of UAE in the DM + Valsartan group at 4 weeks was significantly lower 
A

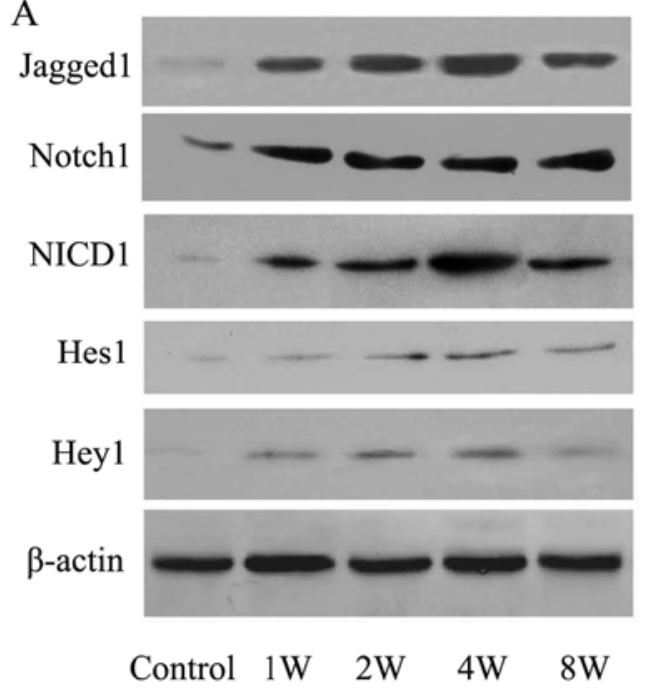

B
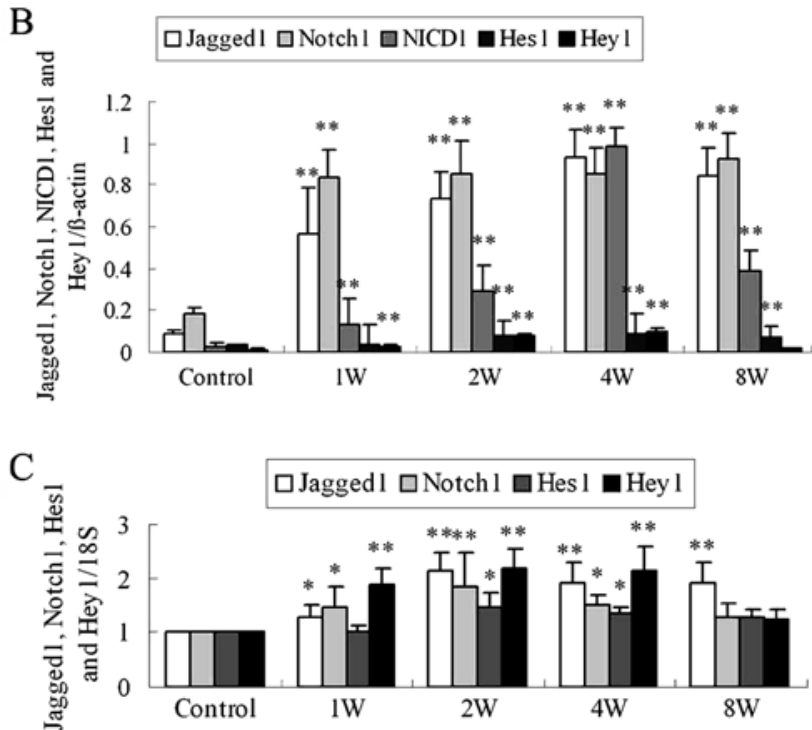

Figure 1. Expression of Jagged1, Notch1, Notch intracellular domain 1 (NICD1), Hes family BHLH transcription factor 1 (Hes1) and Hes-related family BHLH transcription factor with YRPW motif 1 expression (Heyl) in the glomeruli of the control and diabetes mellitus (DM) groups (at 1,2, 4 and 8 weeks). (A and B) Protein expression of Jagged1, Notch1, NICD1, Hes1 and Hey1 was determined by western blot analysis. (C) The mRNA levels of Jagged1, Notch1, Hes1 and Hey1 were detected using RT-qPCR. Data are expressed as the means \pm standard deviation (SD), $\mathrm{n}=6 .{ }^{*} \mathrm{P}<0.05$ and ${ }^{* * *} \mathrm{P}<0.01$ vs. the control group.

compared with that of the DM group $(\mathrm{P}<0.05)$, but both groups still had higher UAE levels than the control group $(\mathrm{P}<0.01)$. The size of the kidney, which was evaluated by calculating the ratio of kidney weight/body weight (KW/BW), significantly increased in the DM group at 4 weeks compared with the control group; treatment with Valsartan was associated with a significant reduction in the $\mathrm{KG} / \mathrm{BG}$ ratio compared with the DM group $(\mathrm{P}<0.05)$. In addition, the mean glomerular diameter (MGD) was significantly increased in the DM group at 4 weeks compared with the control group $(\mathrm{P}<0.01)$; Valsartan treatment significantly inhibited glomerular hypertrophy $(\mathrm{P}<0.01)$.

Morphological changes in glomeruli of diabetic mice. Pathological changes were not observed in the glomeruli of mice in the control group. However, the basement membrane was thickened and the mesangial matrix was increased in the DM group at 4 weeks. Valsartan treatment significantly attenuated the pathological changes in glomeruli, as compared to the DM group (Fig. 2).

Valsartaninhibits the activationof the Notchpathwayin the glomeruli of diabetic mice. Immunohistochemical staining (Fig. 3) revealed that Notch1 and NICD1 protein expression was detected in the glomeruli and tubules. Notch1 protein expression was increased in the glomeruli of the DM group at 4 weeks compared with the control group; in the DM + Valsartan group, Notch1 expression was significantly lower in the glomeruli than the DM group $(\mathrm{P}<0.01)$. NICD1-positive cells were significantly increased in the glomeruli of the DM group at 4 weeks $(\mathrm{P}<0.01)$. Moreover, Valsartan reduced the number of NICD1-positive cells in the glomeruli of diabetic mice $(\mathrm{P}<0.01)$. In the present study, using western blot analysis (Fig. 4A and B), we noted that the protein levels of Jagged1, Notch1, NICD1, Hes1 and Heyl were markedly higher in the glomeruli of diabetic mice at 4 weeks than in control mice and were significantly reduced in response to Valsartan treatment $(\mathrm{P}<0.05$ or $\mathrm{P}<0.01)$. RT-qPCR revealed similar changes in Jagged1, Notch1, Hes1 and Hey1 mRNA levels in the glomeruli of diabetic mice after treatment with Valsartan, at 4 weeks ( $\mathrm{P}<0.05$ or $\mathrm{P}<0.01)$ (Fig. 4C).

Valsartan inhibits the Bcl-2 and p53 pathways in the glomeruli of diabetic mice. As shown in Fig. 5, compared with the control group, the expression of Bax and cleaved caspase-3 increased and the expression of Bcl-2 decreased in the glomeruli of mice with STZ-induced diabetes at 4 weeks $(\mathrm{P}<0.01)$. Alterations in Bax, cleaved caspase-3 and Bcl-2 protein levels in mice in the DM group were ameliorated by the addition of Valsartan $(\mathrm{P}<0.01)$. Compared with the glomeruli in the control group, p-p53 (Ser-37) protein expression increased in the DM group at 4 weeks, and treatment with Valsartan decreased p-p53 (Ser-37) protein levels $(\mathrm{P}<0.01)$. Furthermore, total p53 expression did not vary markedly between the control and DM groups and was not markedly affected by treatment with Valsartan $(\mathrm{P}>0.05)$.

Valsartan inhibits cell apoptosis in the glomeruli of diabetic mice. Positive nuclear staining in the glomeruli was noted in the representative images of TUNEL staining (Fig. 6A). Compared with the control group, green fluorescence in the glomeruli of the DM group at 4 weeks was more intense, as noted using fluorescence microscopy. These apoptotic cells disappeared after treatment with Valsartan. Using flow cytometric analysis, the apoptotic rate in the glomeruli of mice in the DM group at 4 weeks was found to be increased compared with that in the control group, and this was significantly inhibited by Valsartan $(\mathrm{P}<0.05$ or $\mathrm{P}<0.01)$ (Fig. 6B and $\mathrm{C})$.

Valsartan decreases the concentration of urinary PCX in mice with STZ-induced diabetes. The concentration of urinary PCX increased in the DM group at 4 weeks compared with the control group $(\mathrm{P}<0.01)$, and in the $\mathrm{DM}+$ Valsartan group, it was significantly lower compared with the DM group $(\mathrm{P}<0.01)$, although it was still higher than the control group (Table I). 


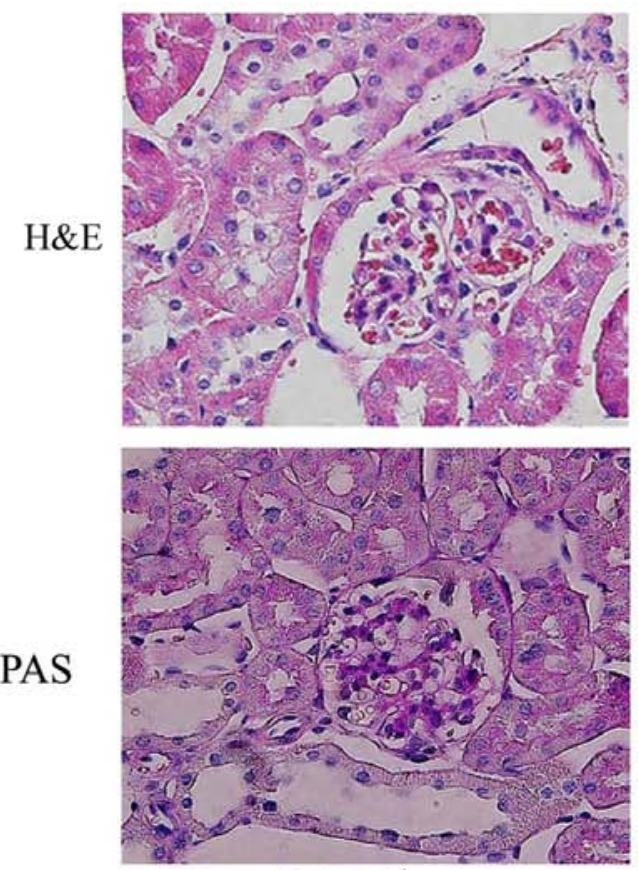

Control
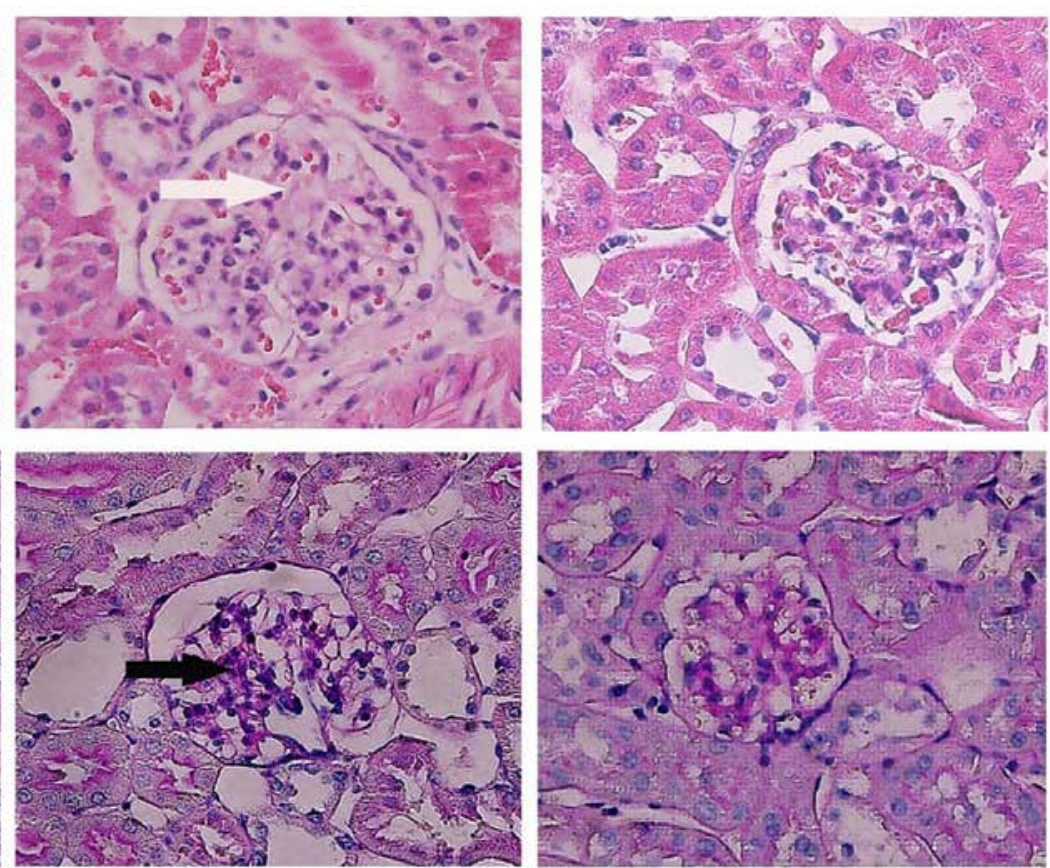

$\mathrm{DM}$

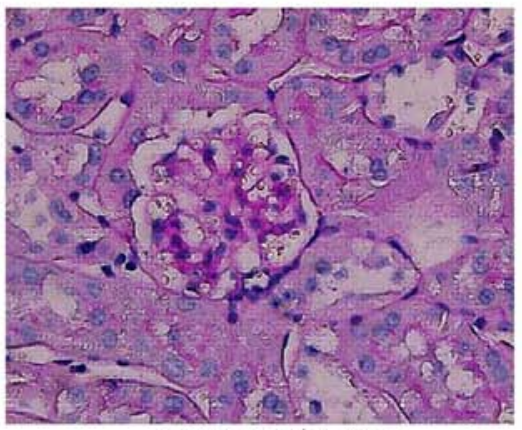

DM+Valsartan

Figure 2. Morphological changes in murine glomeruli. Renal tissue sections obtained from the mice of the control, diabetes mellitus (DM) and DM + Valsartan groups at 4 weeks were stained with H\&E and periodic acid-Schiff (PAS) (magnification, x400). White arrow, expanded mesangial region; black arrow, positive for PAS.
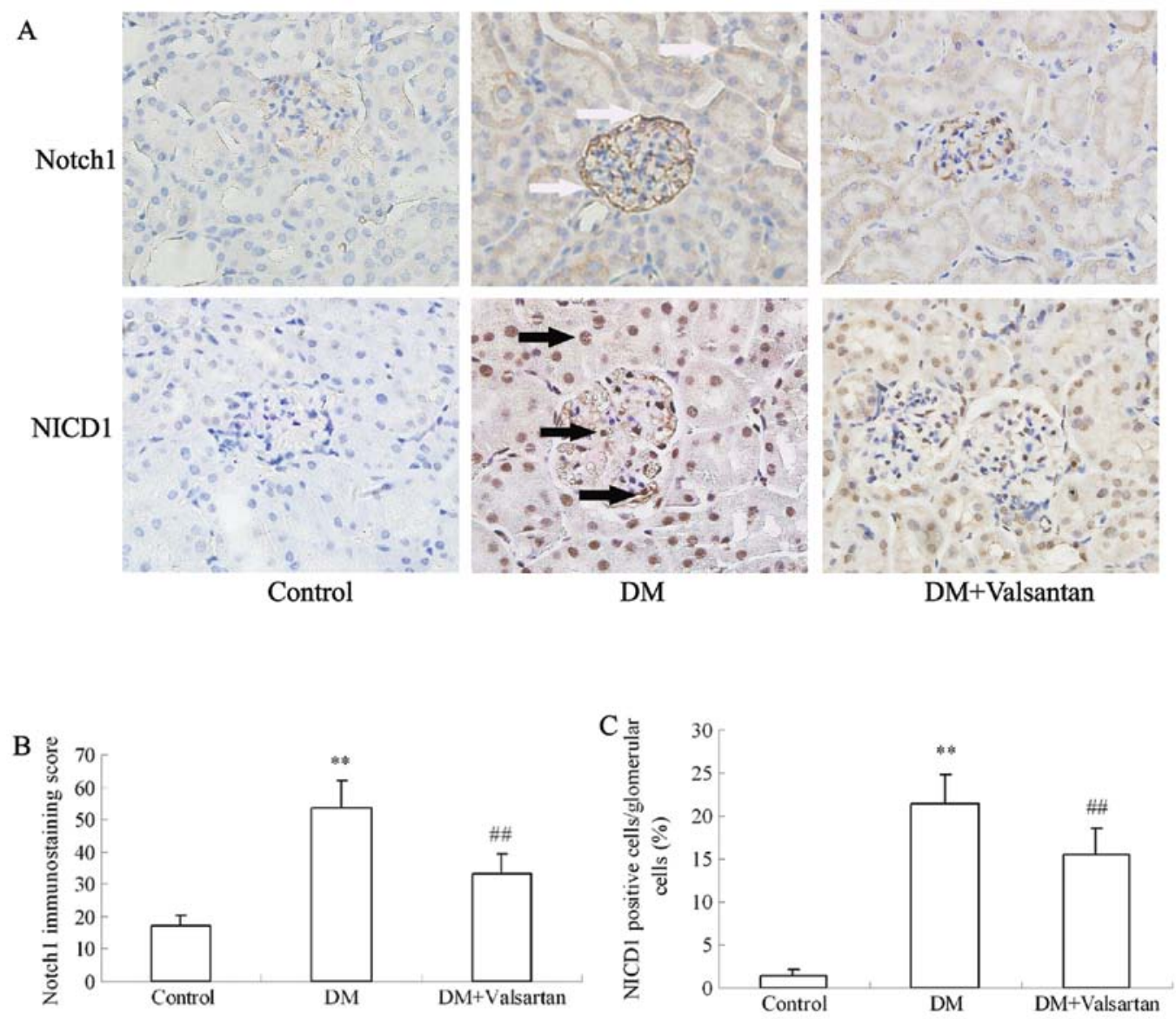

Figure 3. Immunohistochemical analysis showing the effect of Valsartan on the expression of Notch1 and Notch intracellular domain 1 (NICD1) protein in the glomeruli of mice in the control, diabetes mellitus (DM) and DM + Valsartan groups at 4 weeks (magnification, $\mathrm{x} 400$ ). (A and B) Analysis of Notch1 expression in the glomeruli of each group and semiquantitative analysis. (A and C) NICD1-positive cells in glomeruli in the glomeruli of each group. Data are expressed as the means \pm standard deviation $(\mathrm{SD}), \mathrm{n}=6 .{ }^{* *} \mathrm{P}<0.01$ vs. the control group; ${ }^{\# \#} \mathrm{P}<0.01$ vs. the DM group. White arrow, positive anti-Notch1 staining; black arrow, positive anti-NICD1 staining. 
A

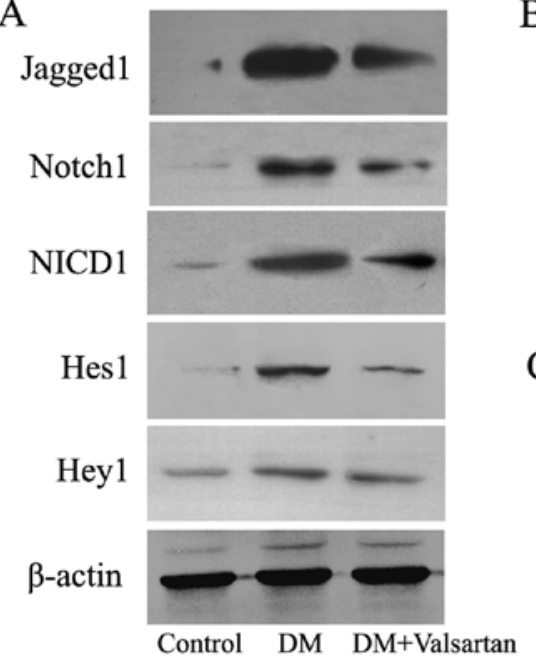

B

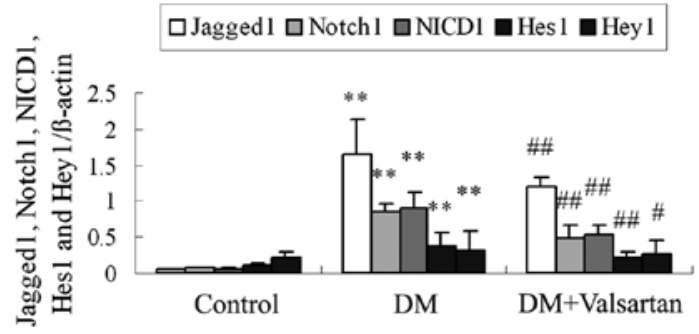

$\mathrm{C}$

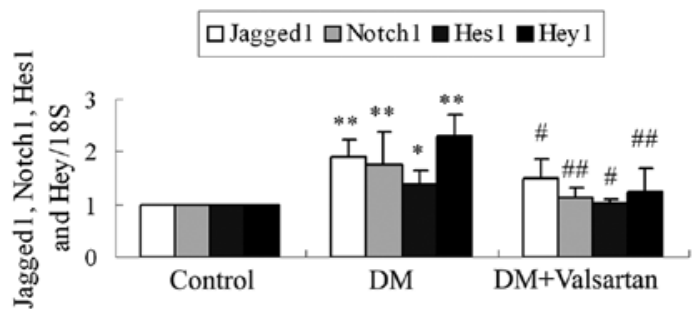

Figure 4. Effect of Valsartan on the expression of Jagged1, Notch1, Notch intracellular domain 1 (NICD1), Hes family BHLH transcription factor 1 (Hes1) and Hes-related family BHLH transcription factor with YRPW motif 1 expression (Heyl) in the glomeruli of mice in the control, diabetes mellitus (DM) and DM + Valsartan groups at 4 weeks. (A and B) Protein expression of Jagged1, Notch1, NICD1, Hes1 and Hey1 was determined using western blot analysis. (C) mRNA levels of Jagged1, Notch1, Hes1 and Hey1 were detected using RT-qPCR. Data are expressed as the means \pm standard deviation (SD), n=6. ${ }^{*} \mathrm{P}<0.05$ and ${ }^{* *} \mathrm{P}<0.01$ vs. the control group; ${ }^{\#} \mathrm{P}<0.05$ and ${ }^{\# \#} \mathrm{P}<0.01$ vs. the $\mathrm{DM}$ group.

A

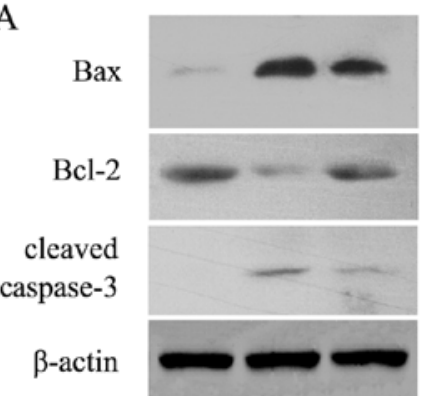

Control DM DM+Valsartan

$\mathrm{C}$

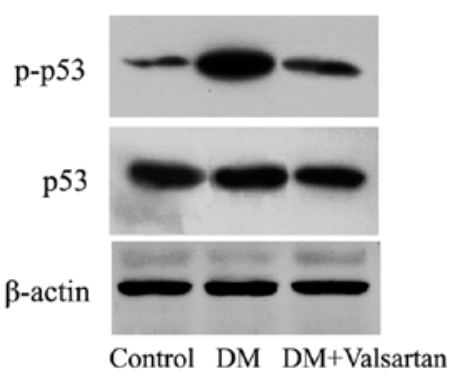

$\mathrm{B}$

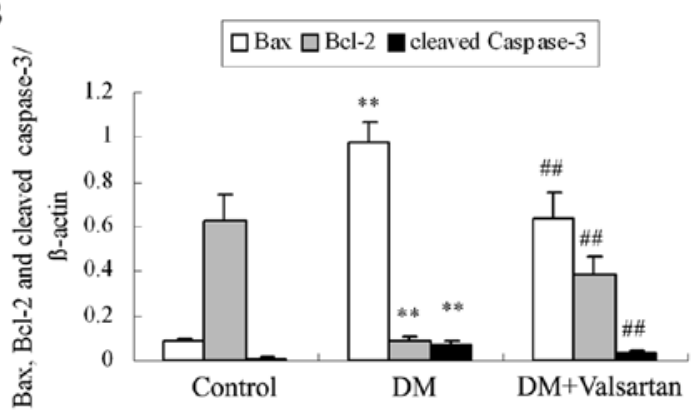

$\mathrm{D}$

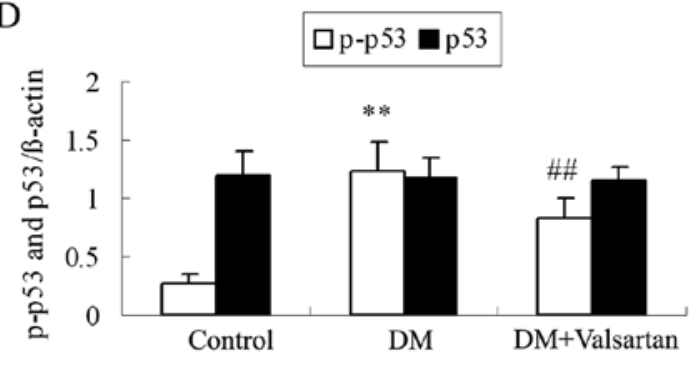

Figure 5. Effect of Valsartan on the protein expression of Bax, B-Cell CLL/Lymphoma 2 (Bcl-2), cleaved caspase-3, p-p53 and p53 in the glomeruli of mice from the control, diabetes mellitus (DM) and DM + Valsartan groups at 4 weeks. (A and B) The protein levels of Bax, Bcl-2 and cleaved caspase- 3 were determined using western blot analysis. (C and D) The protein levels of p-p53 and p53 were determined using western blot analysis. Data are expressed as the means \pm standard deviation (SD), $\mathrm{n}=6 .{ }^{* *} \mathrm{P}<0.01$ vs. the control group; ${ }^{\# \#} \mathrm{P}<0.01$ vs. the DM group.

Valsartan increases the number of podocytes in the glomeruli of diabetic mice. To measure the effects of Valsartan on the number of podocytes, we examined the 3 groups (control, DM, $\mathrm{DM}+$ Valsartan) for WT-1 positive cells using sections taken from the left kidney (Fig. 7). The number of WT-1-positive cells (podocytes)/glomerular tufts was lower in the DM group than that in the control group $(\mathrm{P}<0.05)$. Valsartan increased the number of WT-1-positive cells in mice with STZ-induced diabetes $(\mathrm{P}<0.05)$.

\section{Discussion}

The Notch pathway is an evolutionarily conserved, local cell-signaling mechanism that participates in a variety of cellular processes and is important in glomerular development $(21,22)$. Detailed analyses of the expression pattern of Notch and related genes during nephrogenesis have been performed. Cheng et al (21) used $\gamma$-secretase inhibitor to suppress the activation of the Notch pathway in mouse metanephroi and 


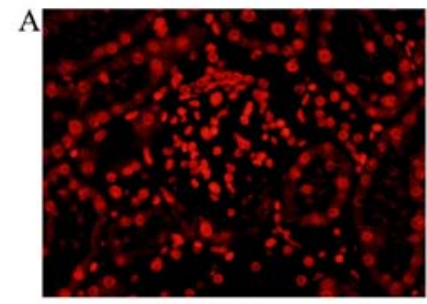

Control

B

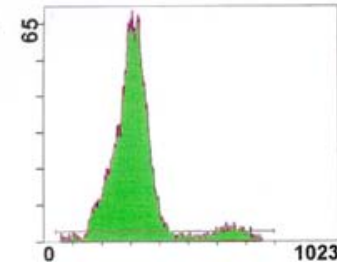

Control

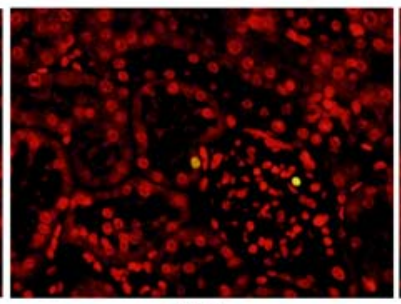

DM

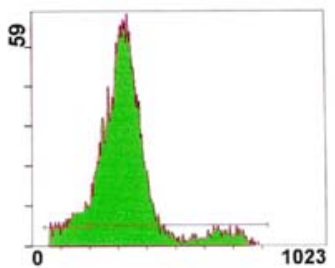

$\mathrm{DM}$

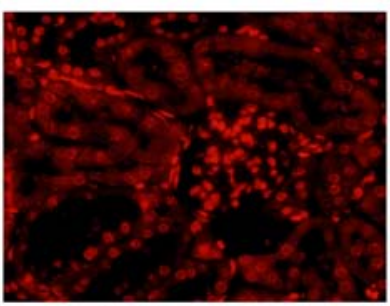

DM+Valsartan

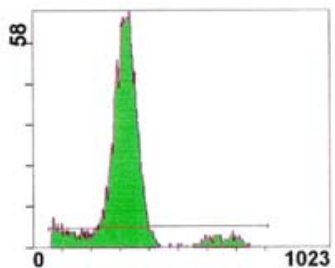

DM+Valsartan

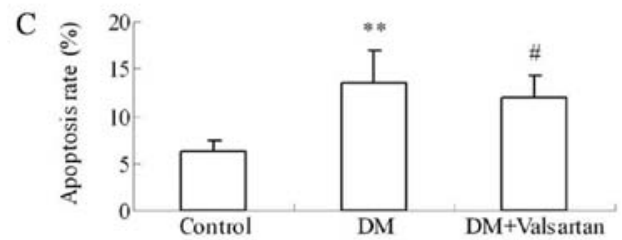

Figure 6. Effect of Valsartan on cell apoptosis in mice in the control, diabetes mellitus (DM) and DM + Valsartan groups at 4 weeks. (A) TUNEL-stained renal tissue sections displayed green fluorescence for apoptotic cells (magnification, $\mathrm{x} 400$ ). (B and C) Cell apoptosis of the glomeruli was examined using flow cytometric analysis. Data are expressed as the means \pm standard deviation $(\mathrm{SD}), \mathrm{n}=6 .{ }^{* *} \mathrm{P}<0.01$ vs. the control group; ${ }^{\mathrm{P}}<0.05$ vs. the $\mathrm{DM}$ group.

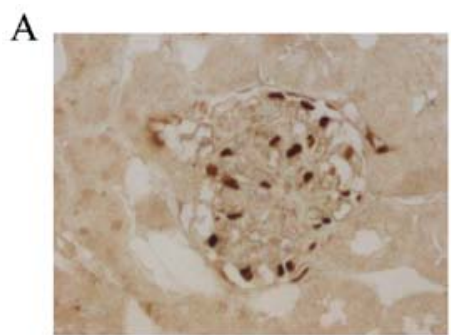

Control

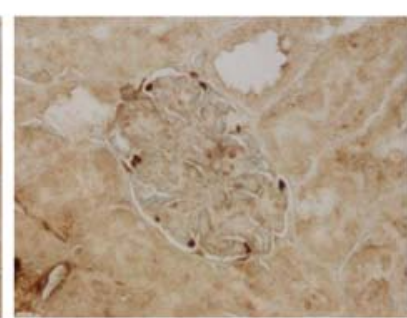

$\mathrm{DM}$

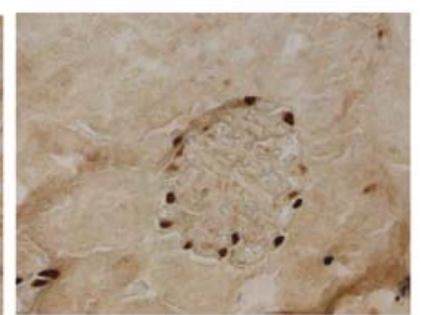

DM+Valsartan

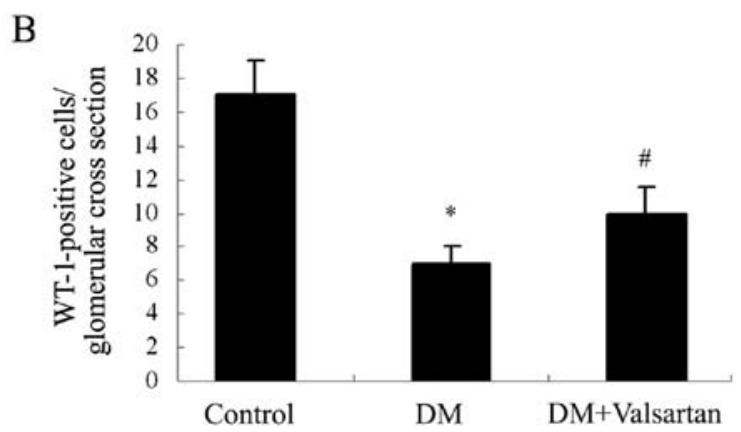

Figure 7. Effect of Valsartan on the number of podocytes in the control, diabetes mellitus (DM) and DM + Valsartan groups at 4 weeks, as shown using (A) immunohistochemical analysis for Wilms tumor-1 (WT-1) (magnification, x400). (B) Quantification of WT-1-positive cells/glomerular cross section for each group. Data are expressed as the means \pm standard deviation $(\mathrm{SD}), \mathrm{n}=6 .{ }^{*} \mathrm{P}<0.05$ vs. the control group; ${ }^{*} \mathrm{P}<0.05$ vs. the DM group.

found fewer renal epithelial structures and low quantities of proximal tubules and glomerular podocytes, which were accompanied by an increase in intervening, non-epithelial cells. However, ectopic activation of the Notch pathway in developing podocytes of Notch-IC-expressing mice caused glomerulosclerosis and opposed terminal differentiation of podocytes (22). In the present study, we demonstrated that the Notch pathway was activated in DM mice, and maximum Notch expression was observed at 4 weeks in the glomeruli of mice with STZ-induced diabetes. Overexpression and binding 
of Jagged1 and Notch1 were likely to be responsible for Notch1 cleavage and activation. Previous research has demonstrated that NICD1, the activated form of Notch1, is translocated into the nucleus where it activates the Hes1 and Heyl genes in diabetic mice $(23,24)$.

It is important to bear in mind that podocytes are an essential component of the glomerular filter $(5,25)$. Clinical and experimental data support the theory that primary podocyte injury is a key step in the development of glomerular disease, which results in severe proteinuria $(26,27)$. Histopathological patterns of glomerulopathy and the quantitative analysis of the number of podocytes have recently been undertaken in research on podocyte injury (6). When podocytes are lost via apoptosis or detachment into the urinary space, the remaining cells have only very limited ability to proliferate and re-cover the 'bare' areas of the glomerular filtration barrier (28). The critical role which the number of podocytes plays and the development of glomerulosclerosis have been demonstrated in type I and type II diabetic kidney disease (29). In the present study, we found that the Notch pathway was activated in mice with STZ-induced diabetes, and this was accompanied by apoptosis and detachment of podocytes. Our previous study has revealed that high glucose induced podocyte apoptosis in vitro through activation of the Notch pathway (30). In addition, the conditional activation of Notch1 protein in NICD1 transgenic mice induced a marked reduction in podocyte-specific markers and resulted in proteinuria and severe glomerular sclerosis $(15,22)$. Taken together, these studies suggest that the activation of the podocyte-specific Notch pathway plays a critical role in the development of proteinuria and glomerular fibrosis in diabetes.

Despite several recent advances, the pathogenesis of DN remains unclear and this accounts for the ineffectiveness of currently available interventions. Hemodynamic alteration in DN induces a higher level of Ang II, which damages podocytes and results in proteinuria via different mechanisms (31). Angiotensin-converting enzyme inhibitor (ACEI) and/or AT1Ra are currently the only drugs that effectively slow the progression of DN (32). Clinical trials have demonstrated that AT1Ras lower the risk of diabetic patients in terms of kidney damage compared with other antihypertensive therapies, and also induce positive effects other than blood pressure-lowering effects (33). In the present study, mice with STZ-induced diabetes were treated with Valsartan, an AT1Ra, to determine its effect on the Notch pathway. Our experiments indicated that Valsartan inhibited the activation of the Notch pathway in the glomeruli of diabetic mice.

It has been demonstrated that the $\mathrm{Bax} / \mathrm{Bcl}-2$ ratio and $\mathrm{p} 53$ levels correlate with cell apoptosis in diabetic rats. Taurine administration decreased the elevated BG and proinflammatory cytokine levels, reduced renal oxidative stress, improved the renal function of diabetic rats and protected renal tissue from alloxan-induced apoptosis by regulating the $\mathrm{Bcl}-2$ family and caspase-3 proteins (34). In vitro, Bcl-2-modifying factor cDNA overexpression in renal proximal tubular cells coimmunoprecipated with Bcl-2, enhanced caspase- 3 activity and promoted apoptosis (35). The severity of acute kidney injury in diabetic mice induced renal proximal tubular cell apoptosis by activating p53 (36). Huang et al (37) demonstrated that a triterpenoid exerted a potent effect in terms of stimulating p53-mediated cell cycle arrest, resulting in cell apoptosis via activation of caspase- 3 in a human hepatoma cell line.

In the present study, we found that activation of the Notch pathway was accompanied by higher levels of Bax/Bcl-2 and p53 phosphorylation in the glomeruli of mice with STZ-induced diabetes. Furthermore, higher NICD1, upregulated Hes1 and Heyl expression, enhanced Bax and p-p53 levels, inhibited Bcl-2 protein expression and associated upregulation of cleaved caspase-3 were all noted. Certain studies have found that Hes1 and Heyl activated the Bcl-2 and p53 pathways, and induced cell apoptosis in epithelial and glioma cells $(38,39)$. In the present study, we found that Valsartan ameliorated cell apoptosis in the glomeruli of with STZ-induced diabetes by inhibiting the activation of the Notch pathway and suppressing Bcl-2 and p53 apoptotic pathways. Valsartan treatment also reduced podocyte detachment from the glomerular basement membrane. It appears that therapy with Valsartan directly prevents podocyte injury and thereby decrease proteinuria and disease progression in patients with diabetes. Apoptosis and detachment of podocytes result in decreased podocyte density and cause the development of DN (15). Taken together, our results suggest that inhibition of the Notch pathway by Valsartan may be a potential strategy for the treatment of DN.

In conclusion, our data provide evidence for the activation of the Notch pathway in mice with STZ-induced diabetes. Valsartan was found to inhibit the activation of the Notch pathway, and the apoptosis and detachment of podocytes, as well as reducing proteinuria. Thus, we propose that Valsartan is a potential therapy for $\mathrm{DN}$ via the Notch pathway.

\section{Acknowledgements}

The present study was supported by grants from the Hebei Natural Science Foundation of China (H2014206294) and the Department of Health of Hebei Province of China (ZL20140030).

\section{References}

1. Reidy K, Kang HM, Hostetter T and Susztak K: Molecular mechanisms of diabetic kidney disease. J Clin Invest 124: 2333-2340, 2014.

2. Butt A and Riaz S: Study of protein profiling of human urine in diabetic hypertensive nephropathy versus normal healthy controls. Diabetes Technol Ther 12: 379-386, 2010.

3. Piwkowska A, Rogacka D, Audzeyenka I, Jankowski M and Angielski S: High glucose concentration affects the oxidantantioxidant balance in cultured mouse podocytes. J Cell Biochem 112: 1661-1672, 2011.

4. Liu W, Zhang Y, Liu S, Liu Q, Hao J, Shi Y, Zhao S and Duan H: The expression of intermediate filament protein nestin and its association with cyclin-dependent kinase 5 in the glomeruli of rats with diabetic nephropathy. Am J Med Sci 345: 470-477, 2013.

5. Cao Y, Hao Y, Li H, Liu Q, Gao F, Liu W and Duan H: Role of endoplasmic reticulum stress in apoptosis of differentiated mouse podocytes induced by high glucose. Int J Mol Med 33: 809-816, 2014.

6. Li JJ, Kwak SJ, Jung DS, Kim JJ, Yoo TH, Ryu DR, Han SH, Choi HY, Lee JE, Moon SJ, et al: Podocyte biology in diabetic nephropathy. Kidney Int Suppl 106: S36-S42, 2007.

7. Das R, Xu S, Quan X, Nguyen TT, Kong ID, Chung CH, Lee EY, Cha SK and Park KS: Upregulation of mitochondrial Nox4 mediates TGF- $\beta$-induced apoptosis in cultured mouse podocytes. Am J Physiol Renal Physiol 306: F155-F167, 2014.

8. Mertens PR, Raffetseder U and Rauen T: Notch receptors: a new target in glomerular diseases. Nephrol Dial Transplant 23: 2743-2745, 2008 
9. Cook KM and Figg WD: Angiogenesis inhibitors: current strategies and future prospects. CA Cancer J Clin 60: 222-243, 2010.

10. Ji X, Wang Z, Geamanu A, Sarkar FH and Gupta SV: Inhibition of cell growth and induction of apoptosis in non-small cell lung cancer cells by delta-tocotrienol is associated with notch-1 down-regulation. J Cell Biochem 112: 2773-2783, 2011.

11. Bonegio R and Susztak K: Notch signaling in diabetic nephropathy. Exp Cell Res 318: 986-992, 2012.

12. Liu Y: New insights into epithelial-mesenchymal transition in kidney fibrosis. J Am Soc Nephrol 21: 212-222, 2010.

13. Samon JB, Champhekar A, Minter LM, Telfer JC, Miele L, Fauq A, Das P, Golde TE and Osborne BA: Notch1 and TGFbetal cooperatively regulate Foxp3 expression and the maintenance of peripheral regulatory T cells. Blood 112: 1813-1821, 2008.

14. Ntziachristos P, Lim JS, Sage J and Aifantis I: From fly wings to targeted cancer therapies: a centennial for notch signaling. Cancer Cell 25: 318-334, 2014.

15. Niranjan T, Bielesz B, Gruenwald A, Ponda MP, Kopp JB, Thomas DB and Susztak K: The Notch pathway in podocytes plays a role in the development of glomerular disease. Nat Med 14: 290-298, 2008

16. Weil EJ, Lemley KV, Mason CC, Yee B, Jones LI, Blouch K, Lovato T, Richardson M, Myers BD and Nelson RG: Podocyte detachment and reduced glomerular capillary endothelial fenestration promote kidney disease in type 2 diabetic nephropathy. Kidney Int 82: 1010-1017, 2012.

17. Mavrakanas TA, Gariani K and Martin PY: Mineralocorticoid receptor blockade in addition to angiotensin converting enzyme inhibitor or angiotensin II receptor blocker treatment: an emerging paradigm in diabetic nephropathy: a systematic review. Eur J Intern Med 25: 173-176, 2014.

18. MansourMH,Al-Qattan K, Thomson M and Ali M: Garlic(Allium sativum) down-regulates the expression of angiotensin II AT(1) receptor in adrenal and renal tissues of streptozotocin-induced diabetic rats. Inflammopharmacology 21: 147-159, 2013.

19. Ozasa Y, Akazawa H, Qin Y, Tateno K, Ito K, Kudo-Sakamoto $Y$, Yano M, Yabumoto C, Naito AT, Oka T, et al: Notch activation mediates angiotensin II-induced vascular remodeling by promoting the proliferation and migration of vascular smooth muscle cells. Hypertens Res 36: 859-865, 2013.

20. Johnson RJ, Garcia RL, Pritzl P and Alpers CE: Platelets mediate glomerular cell proliferation in immune complex nephritis induced by anti-mesangial cell antibodies in the rat. Am J Pathol 136: 369-374, 1990 .

21. Cheng HT and Kopan R: The role of Notch signaling in specification of podocyte and proximal tubules within the developing mouse kidney. Kidney Int 68: 1951-1952, 2005.

22. Waters AM, Wu MY, Onay T, Scutaru J, Liu J, Lobe CG, Quaggin SE and Piscione TD: Ectopic notch activation in developing podocytes causes glomerulosclerosis. J Am Soc Nephrol 19: 1139-1157, 2008.

23. Graziani I, Eliasz S, De Marco MA, Chen Y, Pass HI, De May RM, Strack PR, Miele L and Bocchetta M: Opposite effects of Notch-1 and Notch-2 on mesothelioma cell survival under hypoxia are exerted through the Akt pathway. Cancer Res 68: 9678-9685, 2008.

24. Kennard S, Liu H and Lilly B: Transforming growth factor- $\beta$ (TGF-1) down-regulates Notch3 in fibroblasts to promote smooth muscle gene expression. J Biol Chem 283: 1324-1333, 2008.
25. Patrakka J and Tryggvason K: New insights into the role of podocytes in proteinuria. Nat Rev Nephrol 5: 463-468, 2009.

26. Lasagni L, Ballerini L, Angelotti ML, Parente E, Sagrinati C, Mazzinghi B, Peired A, Ronconi E, Becherucci F, Bani D, et al: Notch activation differentially regulates renal progenitors proliferation and differentiation toward the podocyte lineage in glomerular disorders. Stem Cells 28: 1674-1685, 2010.

27. Ueno T, Kobayashi N, Nakayama M, Takashima Y, Ohse T, Pastan I, Pippin JW, Shankland SJ, Uesugi N, Matsusaka T and Nagata M: Aberrant Notch1-dependent effects on glomerular parietal epithelial cells promotes collapsing focal segmental glomerulosclerosis with progressive podocyte loss. Kidney Int 83: 1065-1075, 2013

28. Brosius FC and Coward RJ: Podocytes, signaling pathways, and vascular factors in diabetic kidney disease. Adv Chronic Kidney Dis 21: 304-310, 2014.

29 Wharram BL, Goyal M, Wiggins JE, Sanden SK, Hussain S, Filipiak WE, Saunders TL, Dysko RC, Kohno K, Holzman LB and Wiggins RC: Podocyte depletion causes glomerulosclerosis: Diphtheria toxin-induced podocyte depletion in rats expressing human diphtheria toxin receptor transgene. J Am Soc Nephrol 16: 2941-2952, 2005

30. Gao F, Yao M, Shi Y, Hao J, Ren Y, Liu Q, Wang X and Duan H: Notch pathway is involved in high glucose-induced apoptosis in podocytes via Bcl-2 and p53 pathways. J Cell Biochem 114: 1029-1038, 2013

31. Lai KN, Leung JC and Tang SC: The renin-angiotensin system. Contrib Nephrol 170: 135-144, 2011.

32. Kintscher U, Foryst-Ludwig A and Unger T: Inhibiting angiotensin type 1 receptors as a target for diabetes. Expert Opin Ther Targets 12: 1257-1263, 2008.

33. Fujisawa T, Ikegami H, Ono M, Nishino M, Noso S, Kawabata $Y$ and Ogihara T: Combination of half doses of angiotensin type 1 receptor antagonist and angiotensin-converting enzyme inhibitor in diabetic nephropathy. Am J Hypertens 18: 13-17, 2005.

34 Das J and Sil PC: Taurine ameliorates alloxan-induced diabetic renal injury, oxidative stress-related signaling pathways and apoptosis in rats. Amino Acids 43: 1509-1523, 2012.

35. Lau GJ, Godin N, Maachi H, Lo CS, Wu SJ, Zhu JX, Brezniceanu ML, Chénier I, Fragasso-Marquis J, Lattouf JB, et al: Bcl-2-modifying factor induces renal proximal tubular cell apoptosis in diabetic mice. Diabetes 61: 474-484, 2012.

36. Peng J, Li X, Zhang D, Chen JK, Su Y, Smith SB and Dong Z: Hyperglycemia, p53, and mitochondrial pathway of apoptosis are involved in the susceptibility of diabetic models to ischemic acute kidney injury. Kidney Int 87: 137-150, 2015.

37. Huang J, Tang XH, Ikejima T, Sun XJ, Wang XB, Xi RG and Wu LJ: A new triterpenoid from Panax ginseng exhibits cytotoxicity through p53 and the caspase signaling pathway in the HepG2 cell line. Arch Pharm Res 31: 323-329, 2008.

38. Niimi H, Pardali K, Vanlandewijck M, Heldin $\mathrm{CH}$ and Moustakas A: Notch signaling is necessary for epithelial growth arrest by TGF- $\beta$. J Cell Biol 176: 695-707, 2007.

39. Purow BW, Sundaresan TK, Burdick MJ, Kefas BA, Comeau LD, Hawkinson MP, Su Q, Kotliarov Y, Lee J, Zhang W and Fine HA: Notch-1 regulates transcription of the epidermal growth factor receptor through p53. Carcinogenesis 29: 918-925, 2008. 